of the rectum. The surgeon's hand through the rectal tube has been utilised in post mortem examinations for the abstraction of the kidneys and other small viscera : I mention this only to express my regret that any such underhand examination has been necessitated, by reason of friends negativing an essential but disagreeable duty of our profession in the pursuit of truth.

\section{REMARKS ON THE TREATMENT OF TINEA TONSURANS.}

BY R O B E T J. LEE, M.D., F.R.C.P., Senior Assistant-Physician to the Hospital for Sick Children, Great Ormond Street.

THERE are numerous agents which seem to have more or less active influence in the treatment of ringworm; some being advocated by some practitioners as superior to others, while these again have their own s ipporters. The spores of the trichophyton appear to resemble the microspores lately examined by Professor Tyndall in their obstinate resistance to destruction; and the successful treatment of cases of tinea tonsurans clearly depends on determining whether it is possible to destroy these spores, or whether, by preventing their germination for a certain period, the disease practically cures itself. The observation of some troublesome cases of ringworm which had been under various kinds of treatment without much benefit, suggested a plan of treatment which excluded the possibility of destroying the trichophyton spores, and only had for its object the arrest of proliferation of the germs. The question of the destruction of microspores is one which perhaps does not present itself as quite a different question from the prevention of their development. An example will illustrate what is meant. If we take a solution containing bacteria, such, for instance, as that in which bladders are prepared for museum purposes, the odour of which is singularly powerful, and add to it a certain quantity of carbolic acid solution of the strength of $\mathrm{I}$ in 40 , we shall find that the active living organisms which exist in the former will be instantly destroyed and the odour removed. If we do the same thing with a solution of salicylic acid of full strength (water absorbs only about $I$ in 400) the organisms are not destroyed and the odour is not removed; that is to say, salicylic acid will not destroy well-developed bacteria. But salicylic acid will prevent them from developing, as is proved by the fact that we may preserve animal or vegetable matter from decom. position by treating it with solution of the acid. We thus see the importance of distinguishing between agents which destroy bacteria and microspores, and those which simply prevent their development; and there is no doubt that those who have been studying this most interesting subject by clinical, microscopical, or physical methods are well aware of the importance of ascertaining the conditions which favour or arrest the development of different species of germs ; clearly a stage in the inquiry beyond that of the extent to which the germs may be destroyed by various agents.

As it is well known that some of the remedies used for ringworm are less liable to produce inflammation of the skin than others, it is most desirable to give a preference to the former, the production of inflammatory changes seeming rather to retard than promote the action of a remedy. On this principle I have, during the last twelve months, used carbolic acid, the most certain agent for the prevention of the development as well as for the destruction of microspores, with decidedly better results than were observed when iodine, tincture of the sesquichloride of iron, or any other agents had been employed, including Goa powder, which has lately been recommended as superior to most others. There is one impoitant point which must be attended to under any circumstances; and this is, the necessity of much more frequent application of any remedy than is usually considered requisite, for the reason that most species of microspores require only a few hours to advance from one stage of development to another, and that, in order to prevent any increase in the number of the spores, though we may not be able to destroy them, it is absolutely necessary to apply the remedy at intervals of not less than six hours. The best preparation for this purpose is a combination of sulphur and olive-oil in equal parts, to which carbolic acid in the proportion of two grains to the drachm is added. To prevent the contact of the fingers of the person who applies it, and who is liable, without caution, to take hold of a child by the neck or shoulders, and thus produce the disease on other parts, a small sponge or brush should be used. This must be done every four or six hours, the head being washed with Castile soap and warm water night and morning before the application of the carbolised oil. If a stronger solution of the acid be used, as, for instance, in the proportion of I to 10, it will be found that a certain amount of inflammation is produced, and the frequent application of such a mixture cannot long be pursued. After making various experiments of this kind, I have found the preparation given above most satisfactory, and believe that the treatment of ring. worm with carbolised sulphur oil may be recommended as superior to any other in common use.

As a matter of experiment, there is no doubt as to the fact that no agent with which we are acquainted is to be compared to carbolic acid for the destruction of organic life without destruction of organic matter, and that no agent is so useful in treating parasitic diseases of the skin, from the fact that, in proportion to its destructive action on the organisms which produce them, it is the least injurious to the cutaneous tissue.

Attention to details is of such importance in the treatment of tinea tonsurans, that it is necessary to add to the above directions the remark that the hair should be cut close with scissors, and that the oil should be rubbed into the skin for a few minutes. The treatment should be continued for at least a fortnight after the disease has apparently been cured. Either of the following prescriptions may be used. The first has the advantage of not becoming thick or dry from evaporation, while the second is cleaner and cheaper.

R Sulphuris precipitati, zinci oxidi, $\bar{a} \bar{a} \overline{3}$; olei olivæ f. $\tilde{3} \mathrm{j}$; acidi carbolici gr. xvi.

R Sulphuris precipitati, zinci oxidi, àâ 3 ij ; glycerini, aquæe, āā f. 3 iij ; acidi carbolici gr. xvi.

\section{REPORT OF A CASE OF PARAPLEGIA DEPENDEN'T} UPON SOFTENING OF THE SPINAL CORD.*

By G. H. PHILIPSON, M.A., M.D.Cantab., F.R.C.P.Lond., Professor of Medicine in the University of Durham; Physician to the Newcastle-upon-Tyne Infirmary

WILLIAM M., aged 42, single, an itinerant herbseller, residing in Newcastle-upon-Tyne, was admitted into the Newcastle Infirmary, under my care, November 18 th, 1875. He stated that for three weeks he had been unable to pursue his occupation, in consequence of numbness and a prickling feeling of the lower extremities, and from increasing inability to walk, the right leg being weaker than the left; also, that he had suffered from a dull pain in the lumbar and sacral regions of the spine, accompanied with a tight feeling in the abdomen, and at times from cramp of the calves of both legs. He had been much exposed to the vicissitudes of the weather, having to gain his livelihood by attending upon a stall placed in the streets, and in consequence had suffered greatly from coldness of the extremities, especially the lower.

Upon examination, it was found that his spine was curved, convexoconcave in form, the convexity being situated at the dorsal region and the concavity at the lumbar; the convexity being directed backwards and the concavity forwards. The curvature had existed since he was ten years of age. Upon percussion of the spines of the lower dorsal vertebræ, especially the tenth, there was distinct tenderness. When a sponge dipped in warm water was applied to the spine, a burningr sensation was complained of about the tenth dorsal vertebra, with a natural sense of heat in the vertebræabove. The passage of a piece of ice over the vertebral column produred a sensaition of cold everywhere, except at the level of the tenth dorsal vertebra, at which spot a feeling of heat was experienced. He was able to raise both his legs from the bed, but there was a great tendency to crossing of the leg: one over the other, especially the left over the right. When the sole: of the feet were tickled, the legs were suddenly jerked from the bed, the right more suddenly and more forcibly than the left. When assisted out of bed, he would have fallen to the ground if he had not been supported, and he was quite unable to move the legs as in the act of pro. gression. The sensation of both feet and legs, as also the temperature, was equal. Both legs were wasted, and the muscles were very flabby. $\mathrm{He}$ had full control over the bladder and rectum. The urine was normal in colour, slightly alkaline in reaction, of specific gravity 1028, was free from albumen, but contained an excess of phosphates.

He was ordered to take twenty minims of the liquid extract of ergot, in water, three times each day; and, as the skin over the convexity of the spine and the sacrum was inflamed, he was placed upon aircushions.

November 29th. He expressed himself as having more power in the legs, also said that the extremities were less numb, but still complained of pain in the lower part of the spine and the tight feeling in the abdomen. 
The ergot was increased to thirty minims. The bowels were relieved by enemata.

December I Ith. Voluntarily, he stated that he was continuing to improve, both in power of moving the legs and in feeling. The bowels were acting naturally. The urine was voided without difficulty, and was slightly acis. He was allowed to be placed in an arm-chair at the side of the fire.

January 12th, 1876. During the last two weeks, he had been stationary; had very little complaint of pain, but still the feeling of abdominal tightness. No gain in muscularity. He was ordered to take five grains of the iodide of potassium, ten grains of the bromide of potassium, and one ounce of the decoction of cinchona, three times each day; and in addition to the ordinary full diet, he was allowed four ounces of port-wine daily. Peripheral galvanisation, by means of the interrupted current, was to be employed every alternate day.

January 29th. There was evidence of slight improvement; he was better able to bear the weight of his body when assisted from the bed to the chair. 'The iodide was increased to seven grains and the bromide to fifteen grains, and the galvanism was to be repeated every day.

February 16 th. The iodide was increased to ten grains and the bromide to twenty grains.

February 26th. As very little improvement had been effected, and as his strength and nutrition appeared to be diminished, he was ordered a grain of sulphate of quinine, ten minims of the tincture of the perchloride of iron, and ten minims of the tincture of nux vomica, in water, three times each day.

March 4th. He appeared to be gaining strength

March I Ith. After a sudden change in the weather, from mild to extreme cold, he complained of catarrh, which developed into bronchitis, for which he was given stimulant expectorants.

March 16th. He was coughing up large quantities of tenacious mucus ; and upon auscultation of the chest, loud sonorous and sibilant rhonchi were heard, especially over the sternum and sides of the chest, so loud that the sounds of the heart could not be distinguished.

March 19th. He became gradually weaker, and died at 2 P.M.

NECROPSY, thirty-six hours after death.-Considerable difficulty was experienced in opening the spinal canal, in consequence of the curvature of the spine, and of the lower dorsal and lumbar vertebræ having become ankylosed. After dividing the spinal dura mater, the meningeal vessels, more especially at the lower dorsal region, were noted as more visible than usual. At this situation also the spinal cord was bulged, and was so much softened as to give way in the removal. The sofiened portion was fully one inch in length, corresponded with the tenth dorsal vertebra, was of a creamy-white colour, and at one spot near its centre was changed into a mere pulp, and when submitted to a stream of water was carried away in the current, the surrounding portion being of a pasty putty-like consistence. Upon microscopical examination, the nervous tissue was seen to be broken up and mixed with a number of bodies, known as granule masses, principally composed of fat. Besides these bodies, decaying tubes and the fatty remains of blood-vessels were distinctly recognised. The pericardium was distended with serosity. The heart was covered with lymph, the result of recent pericarditis. The valves of the heart were healthy. The lungs, more especially the right, at their apices were adherent to the chest wall, and were puckered; and, upon section, cretaceous masses were displayed, the remnant of tubercle. The lungs throughout were congested. The bronchial tubes were filled with frothy glairy mucus. The other organs presented nothing abnormal.

REMARKS. - This case has been recorded, not on account of any peculiarity or rarity, but because of the symptoms and sequence of events being characteristic, first, of hyperæmia of the spinal meninges and spinal medulla, and afterwards of organic lesion of the spinal medulla (softening), such being verified by the examination obtained after death ; it being believed that in myelitis there is no abundant interstitial exuda. tion, but that the nerve-elements undergo inflammatory disturbances of nutrition, and finally break down.

Respecting the diagnosis of hyperæmia, this was arrived at from the evidence of impairment of the functions of the spinal marrow, and the indications of irritation; namely, of the motor nerve-fibres by the cramps and twitchings of the sensitive nerve-fibres by the pricking pains and the abnormal sensations, and of the vaso-motor or nutritive nerve-fibres by the wasting of the muscles. It was further surmised that the paralysing lesion was seated in the portion of the cord corresponding to the lower dorsal vertebræ, from the paralysis being limited to the lower extremities, and not implicating the sphincters.

Having in regard the pathology and the diagnosis, the chief indication in the treatment was the diminution of the blood circulating in the spinal canal, and with this design ergot of rye was prescribed; according to Brown-Séquard, no other agent being so efficacious. When the symptoms of irritation, inferred to be dependent upon the hyperæmia, had subsided, and upon the supposition that, as a consequence of the hyperæmia, some serosity or lymph might have been effused, it was deemed expedient to give absorbent remedies.

Later, with the view of maintaining the strength and the nutrition of the system, and of obviating the effect of rest on the paralysed nerves and muscles, tonics were administered, a nourishing diet was allowed, and galvanism was employed; the chief aim being to improve the quality of the blood, and in such manner the vital properties of the nerve-centre.

\section{ON THE USE OF THE TREPHINE IN DEPRESSED FRACTURES OF THE SKULL.*}

\author{
By ROBERT S. HUDSON, M.D., M.Ch., Redruth.
}

THERE is no subject in surgical literature which seems to have created more divergence of opinion than the employment of the trephine in depressed fractures of the cranium. It is now about one hundred years since Percival Pott so modified the shape of the instrument as to render it safe and manageable ; there has been no change in its form since his day; and there can be no more instructive commentary on the everchanging fashions which exist even in surgery, than to read his essay on Injuries of the Head, and compare his conclusions with the practice of our large hospitals at the present time.

In his celebrated essay, Pott betrays neither doubt nor hesitation firm belief in the efficacy of the trephine is evidenced on almost every page; results are narrated which vie in brilliancy with any of the triumphs of modern surgery; yet the same methods for arriving at the truth exist now as then. The astonishing strides made by physics and chemistry during the interval have little bearing on the point at issue ; careful observation, truthful description, and logical deduction can alone help us. How, then, can we explain the revolution involved in the statement that in St. Bartholomew's Hospital, to which Pott's renius added lustre and renown, his views have been discarded, and, for the six years previous to 1867 , the trephine had not been once em. ployed in an injury of the head? (Bryant's Manual of Surgery, Ist edition, page 77). The post mortem records of our large hospitals are more accurate than at any former period, and observations have certainly accumulated; but do these records, when fairly criticised, encourage the dread of the trephine now fashionable, and which almost condemns it to the limbo of forgotten barbarisms? Of late, there have been many indications of a change in surgical opinion on this question; a fatal issue is not now an invariable result; and the addresses at our annual meetings, with the "hospital notes" in our JOURNAL, give abundant evidence that trephines may be employed with benefit, and have some other use than filling up a vacant space in those orthodox boxes of velvet and mahogany in which our instrumentmakers delight.

I am well aware that you have come for a holiday, so I do not pro. pose inflicting on you a dry narration of cases in which the trephine has been successfully employed, nor an analysis of cases in which it should be used or avoided ; I merely wish to bring before you an account of what is thought of it in the mining districts of Cornwall, and ask you to look on the surgical practice of these districts as an important factor in enabling you to arrive at a conclusion as to its employment.

Around Redruth and Camborne, Pott's principles still prevail ; taught by Pott himself to the great grandfathers of the present generation of surgeons-the Pryces, Lanynns, Vincents, and Michells-these principles of surgical interference in head-injuries have been handed down from father to son, from master to pupil, and their utility has been illustrated in numerous cases. I may be pardoned tracing, so far as Redruth is concerned, the chain of connection which links Pott's days with ours. Before 1815, no examinations had to be passed by medical men previously to practice, and few country practitioners voluntarily undertook the labour involved in obtaining the diploma of the College of Surgeons. The apprenticeship system was the ordinary passport to the profession, and those learned in the "art and mystery" of an apothe. cary had charge of the health of nine-tenths of the people of this kingdom. Those of you who have paid any attention to the antiquities, literature, or history of the county of Cornwall, are aware that we are indebted to Pryce's Mineralogia Cornubiensis and Pryce's Cornislz Vocabulary for a great deal of the knowledge which we now possess. According to the late Mr. W. J. Henwood, F.R.S. (Transactions, Royal Institution of Cornwall, vol. $5 \mathrm{I}$ ), the learned author of these

* Read before the South-Western Branch. 